\title{
Identifying hydrological responses of micro-catchments under contrasting land use in the Brazilian Cerrado
}

\section{R. L. B. Nobrega et al.}

Correspondence to: R. L. B. Nobrega (rodolfo.nobrega@geo.uni-goettingen.de)

The copyright of individual parts of the supplement might differ from the CC-BY 3.0 licence. 


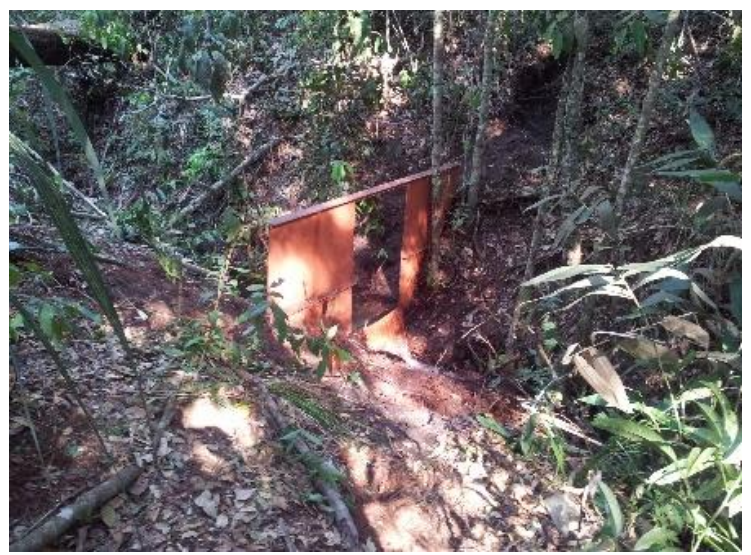

(a) Cerrado

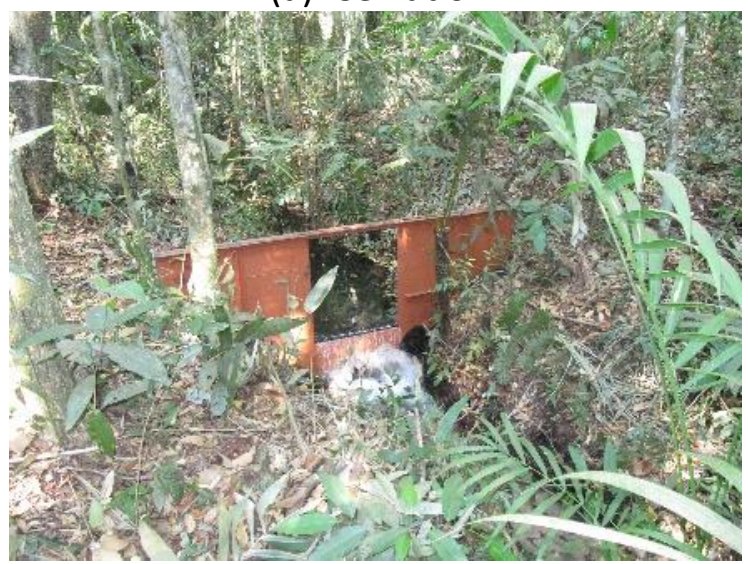

(b) Pasture

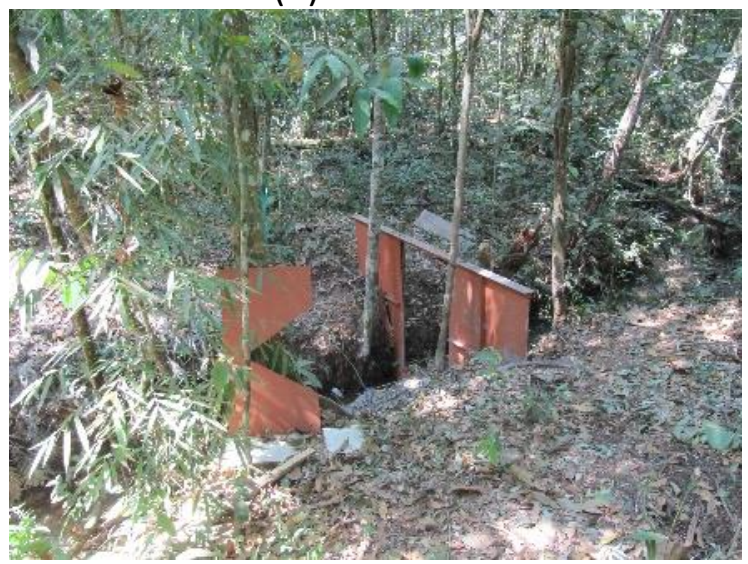

(c) Cropland

Supplement Figure S1 Adjustable weirs at the outlet of each catchment (Photos: R. Nobrega). 


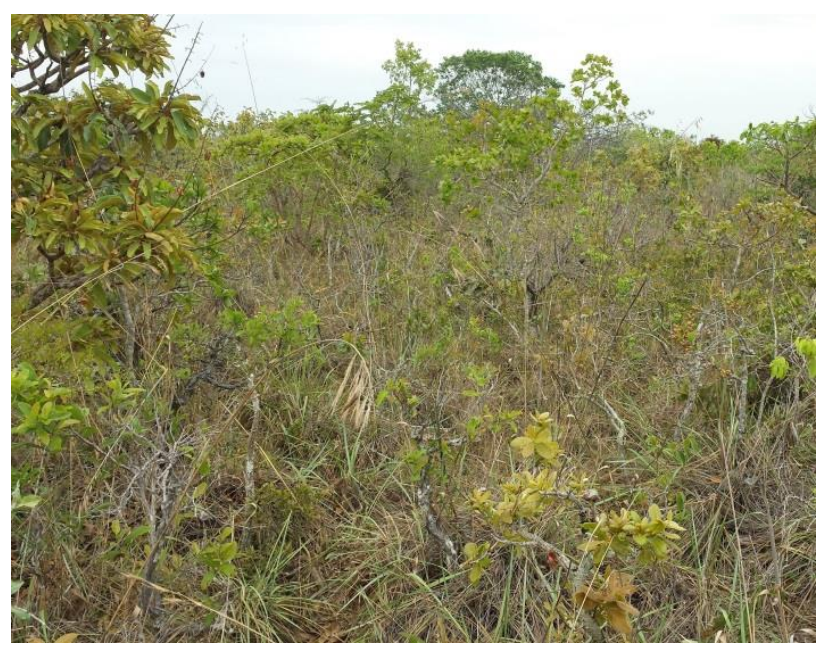

Supplement Figure S2 Cerrado sensu stricto vegetation in the cerrado catchment (Photo: R. Nobrega). 


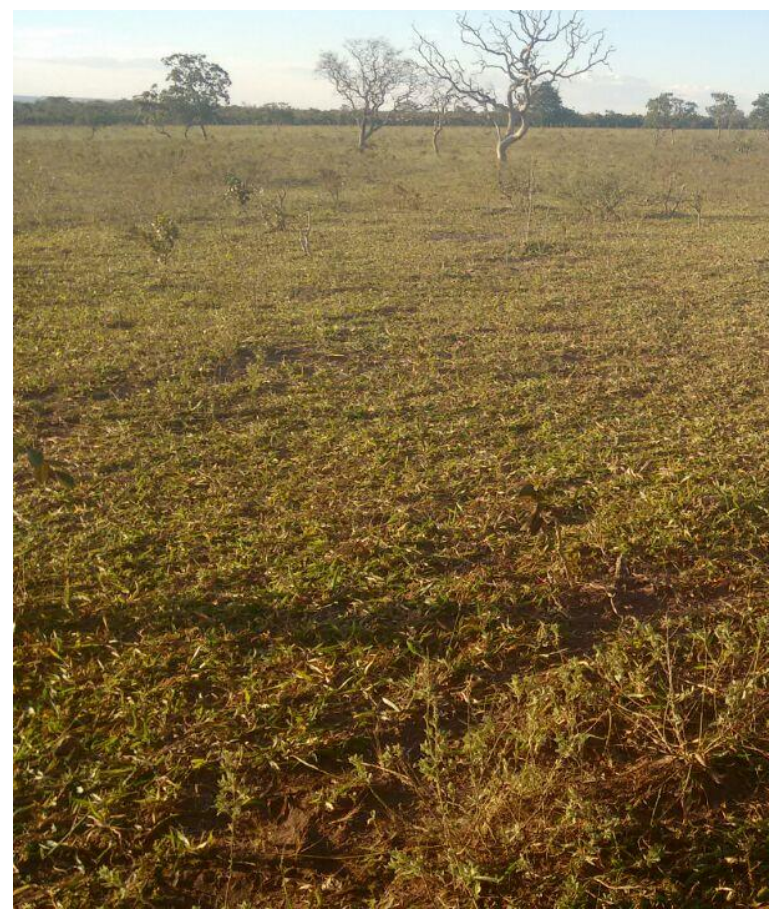

(a)

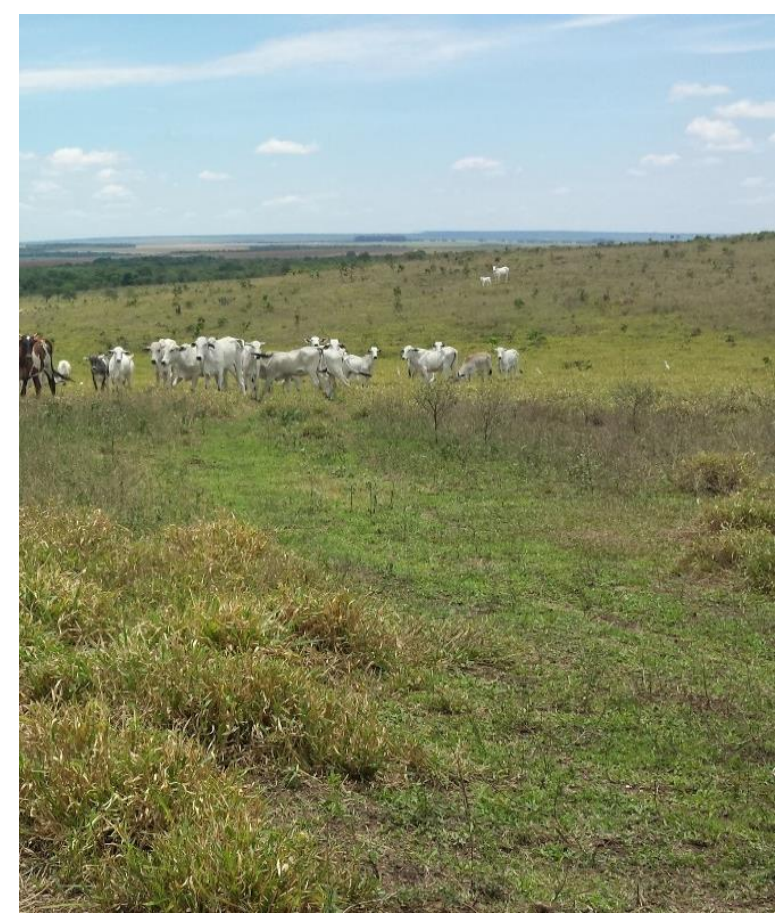

(b)

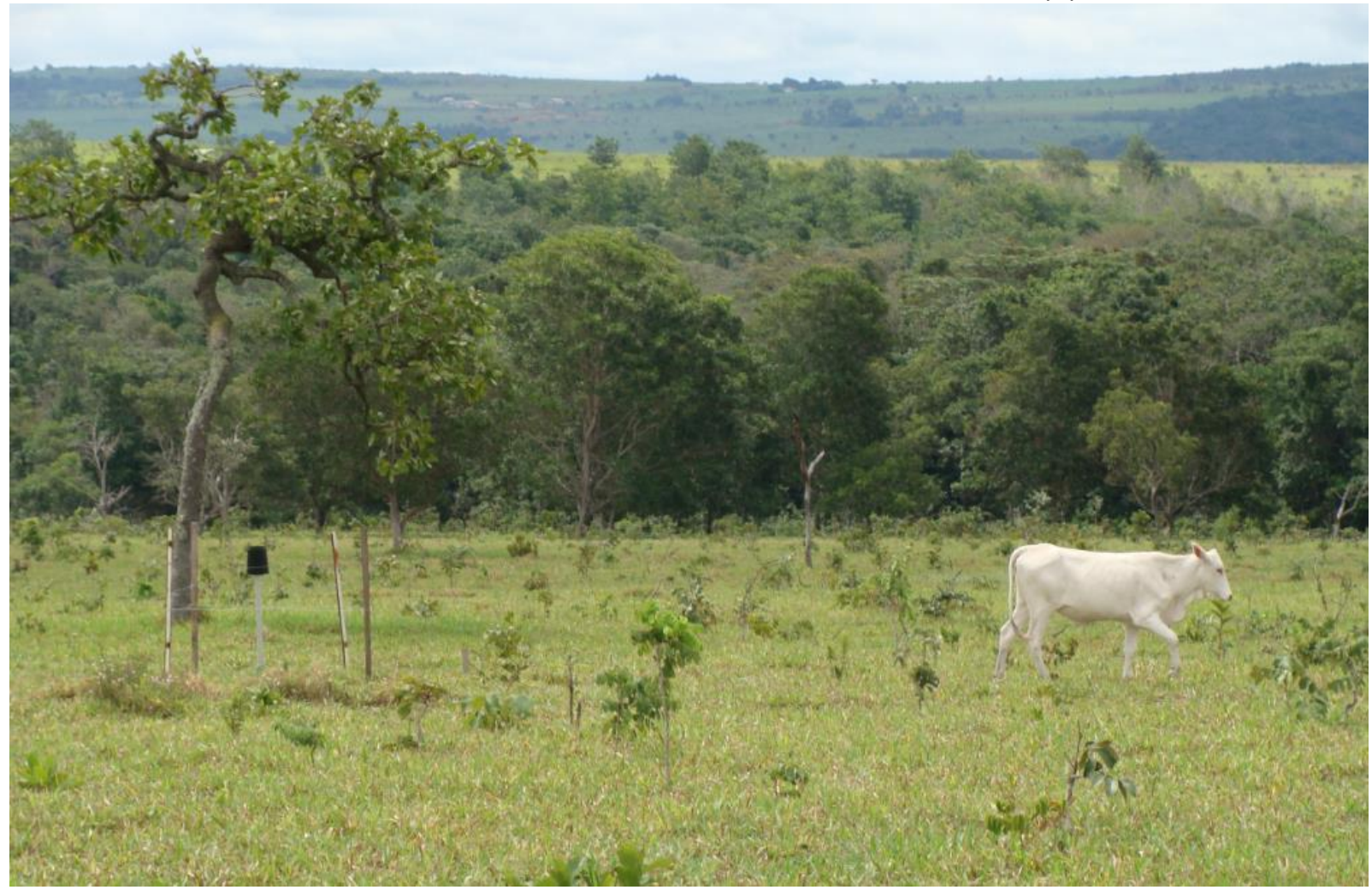

(c)

Supplement Figure S3 Pasture catchment during (a) dry and (b/c) wet seasons (Photo: R. Nobrega). 


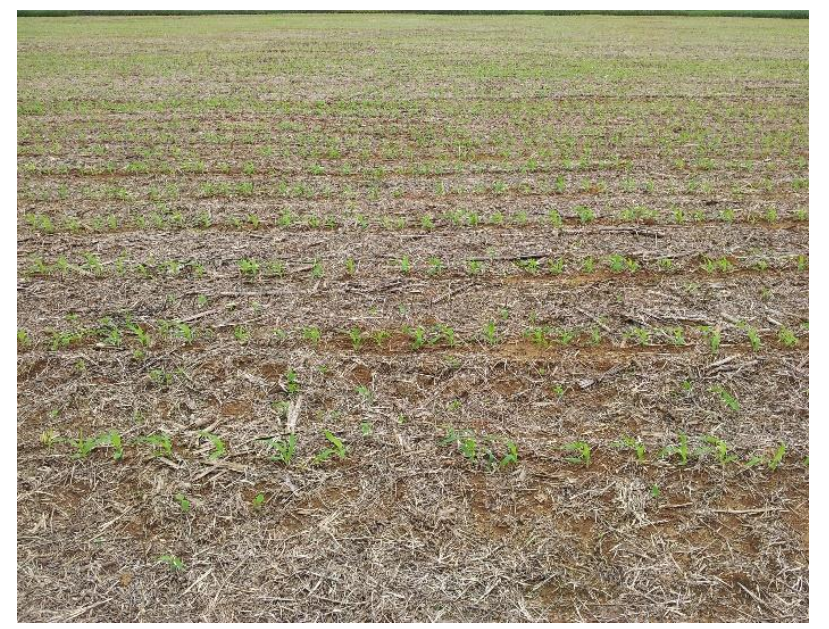

(a)

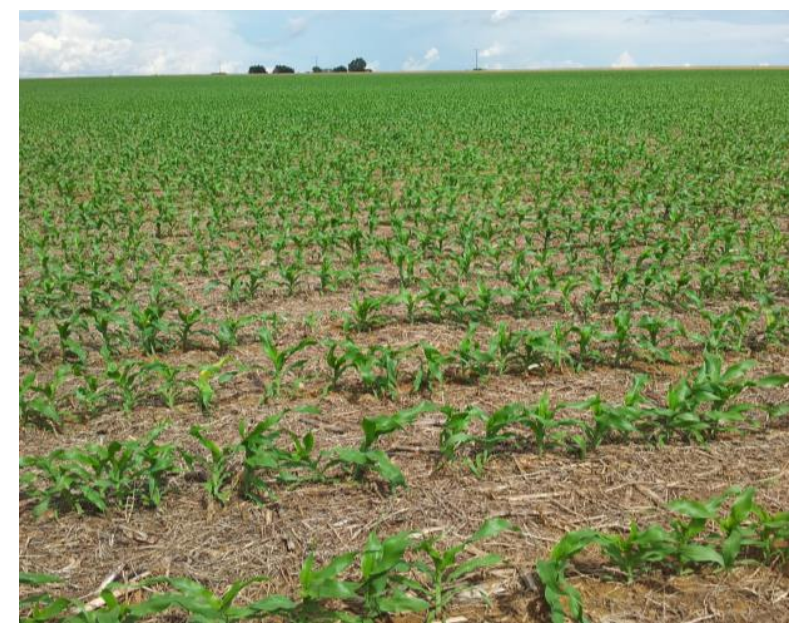

(b)

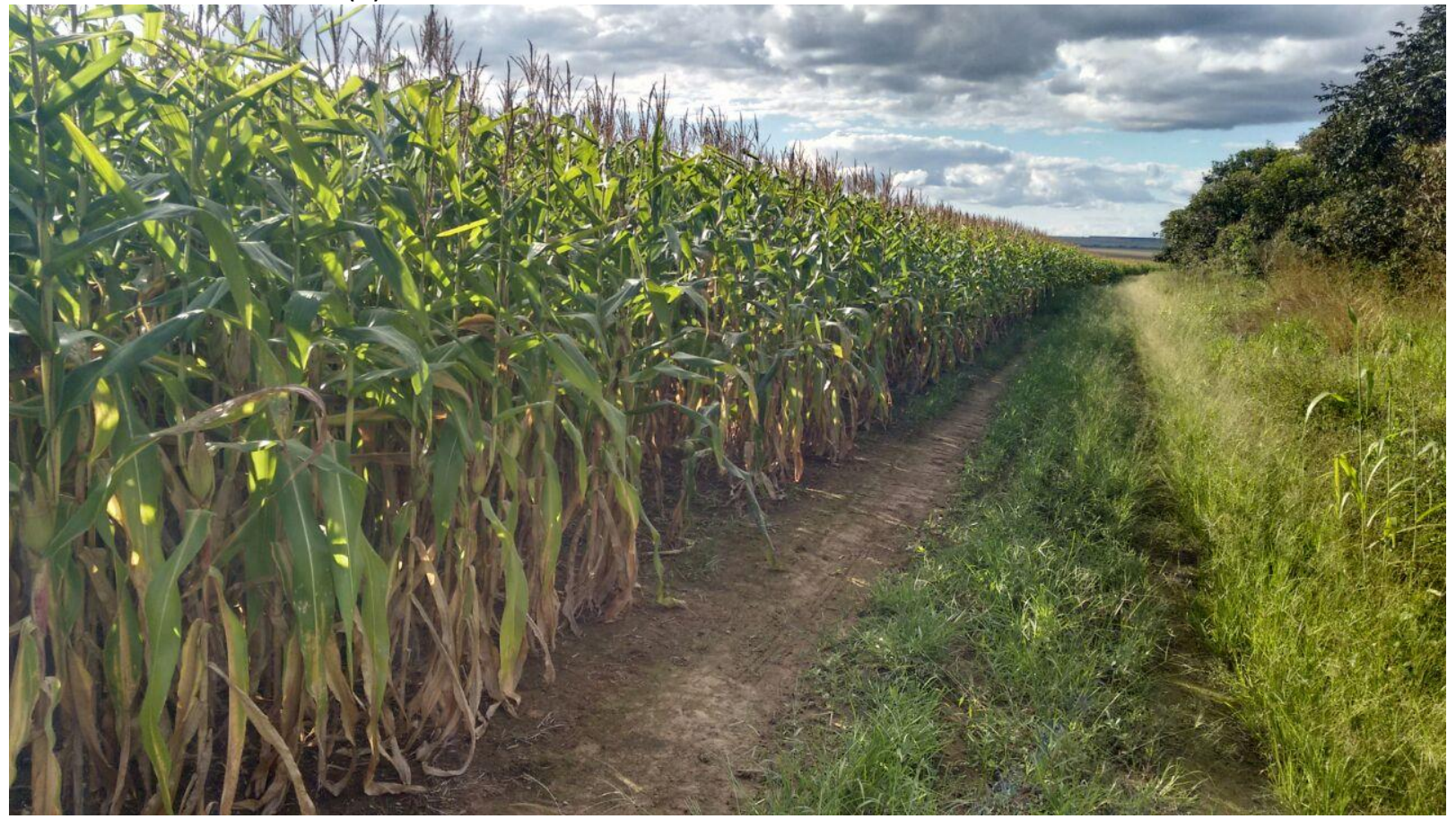

(c)

Supplement Figure S4 Maize growth development at (a/b) early stages and (c) a view of the boundary between the cropland and the riparian zone (Photos: R. Nobrega and T. Santos). 


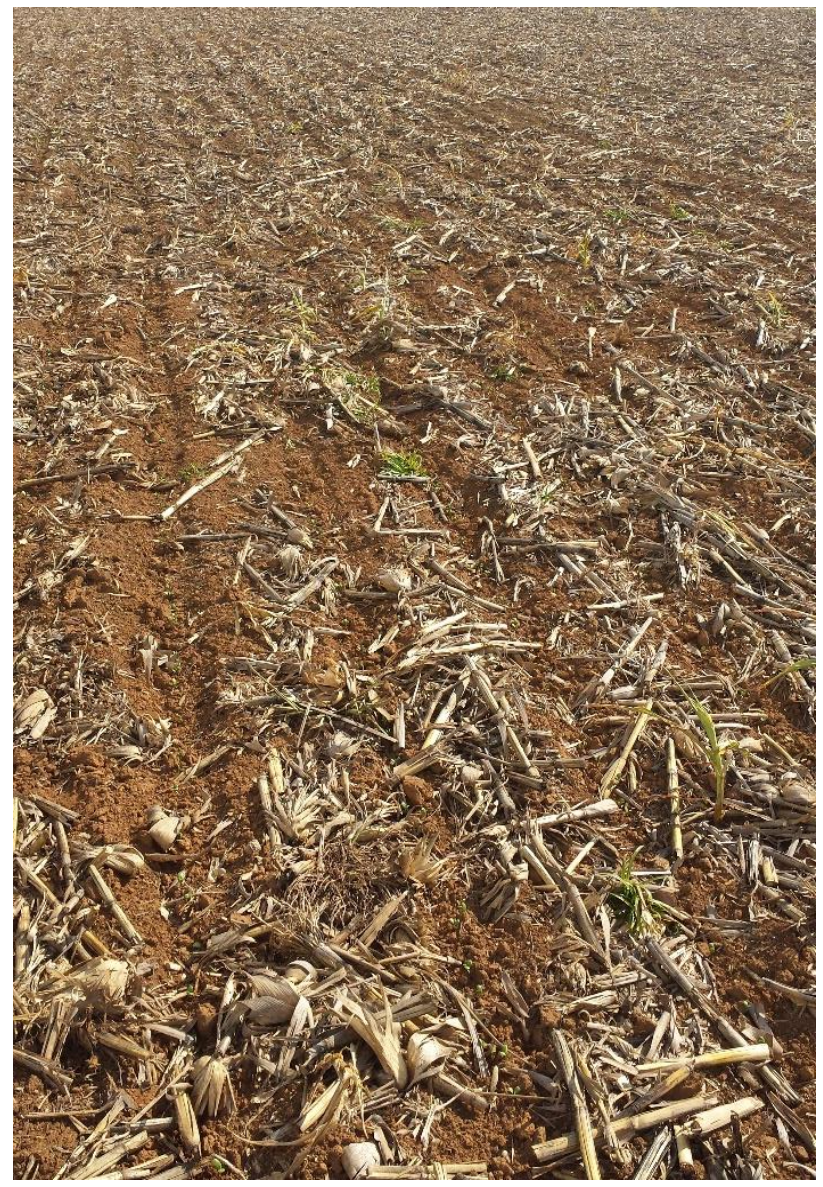

(a)

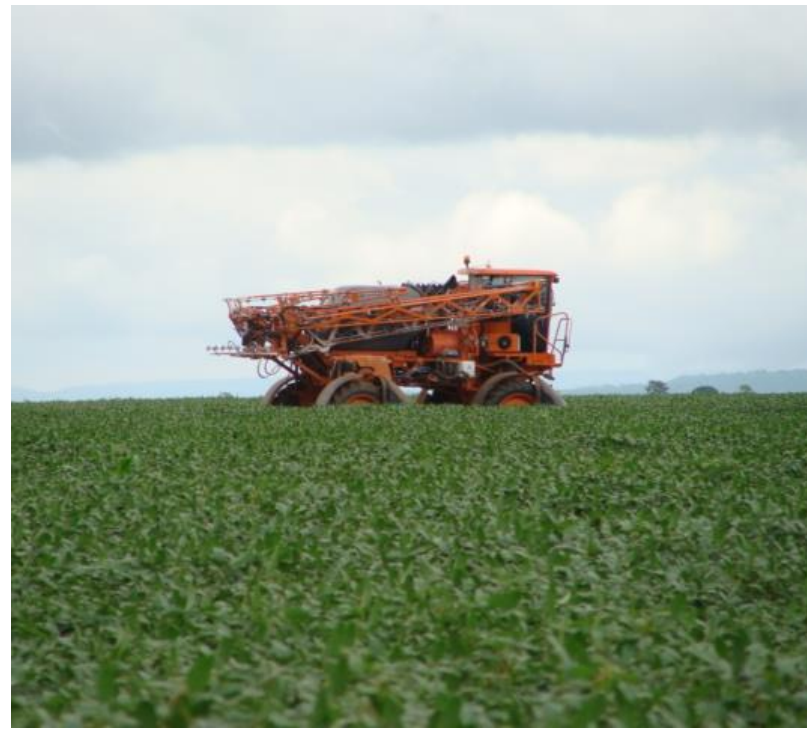

(d)

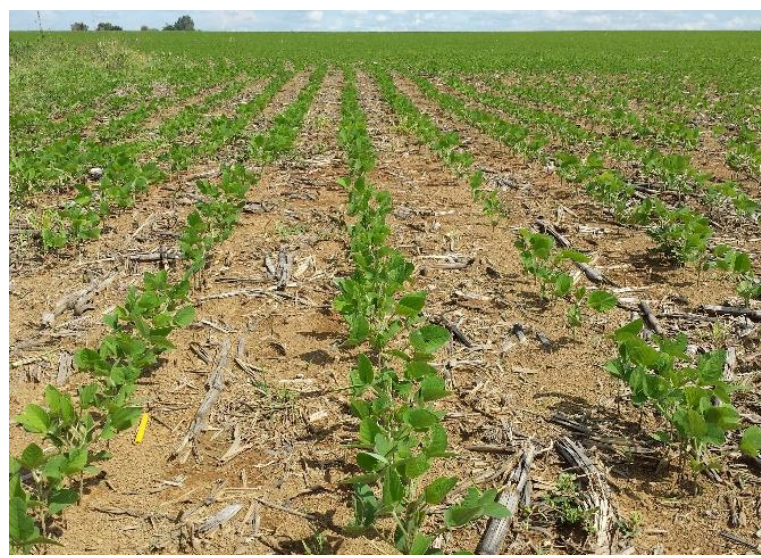

(b)

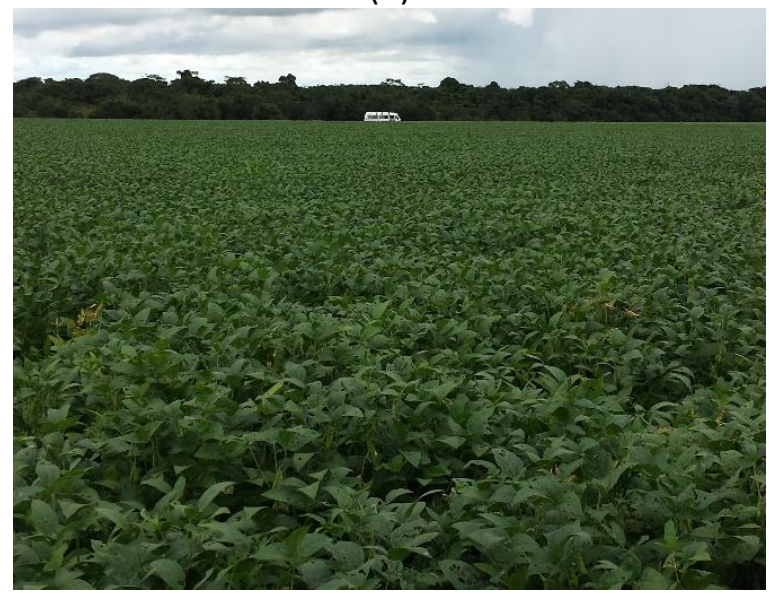

(c)

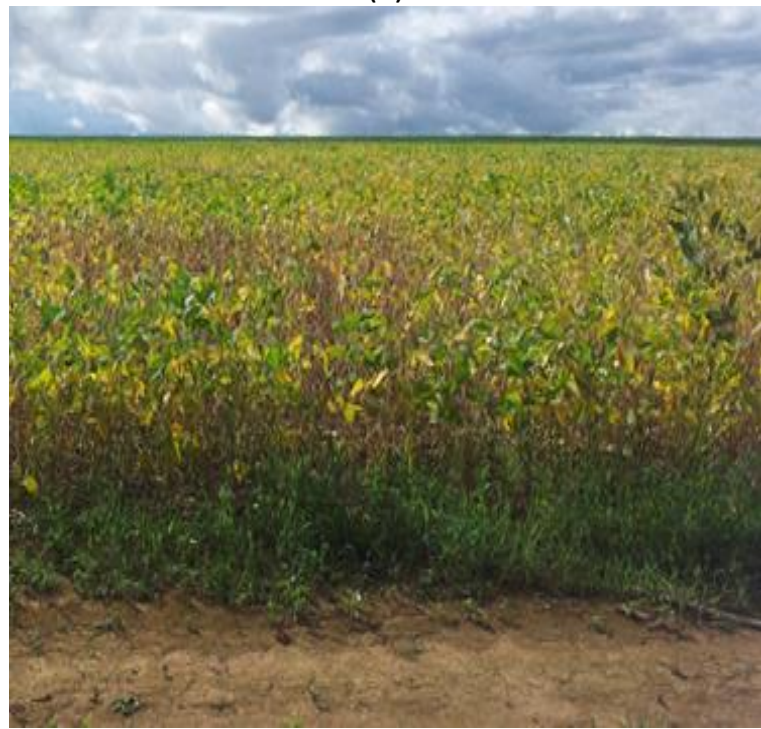

(e)

Supplement Figure S5 Soy bean crop development in the cropland catchment (Photos: R. Nobrega). 

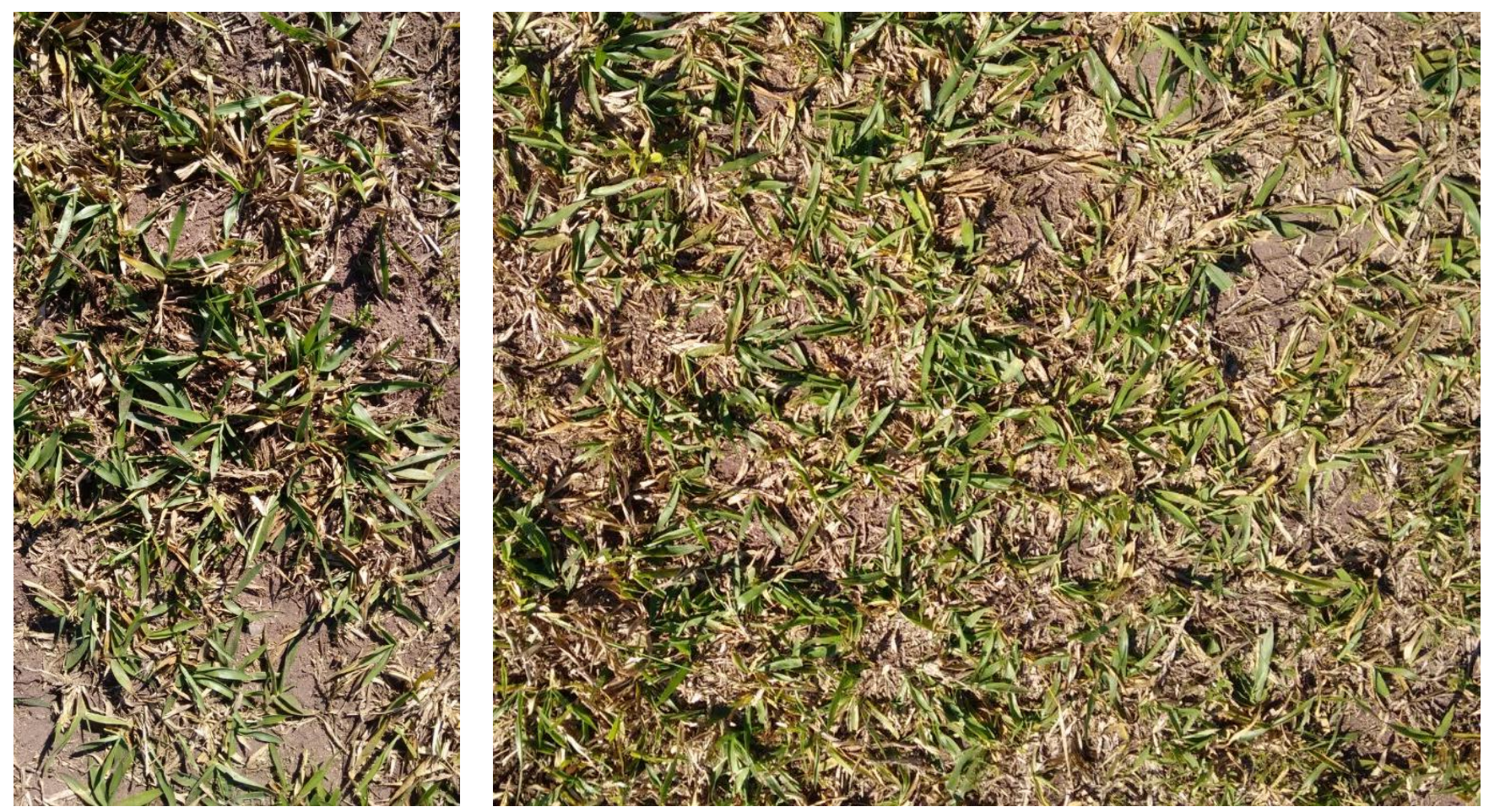

Supplement Figure S6 Grassland degradation aspect in some parts of the Pasture catchment (Photos:T. Santos). 


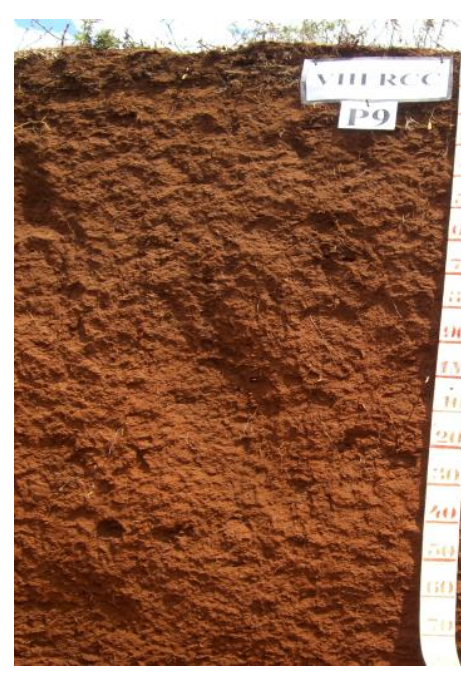

Source: EMBRAPA, 2015

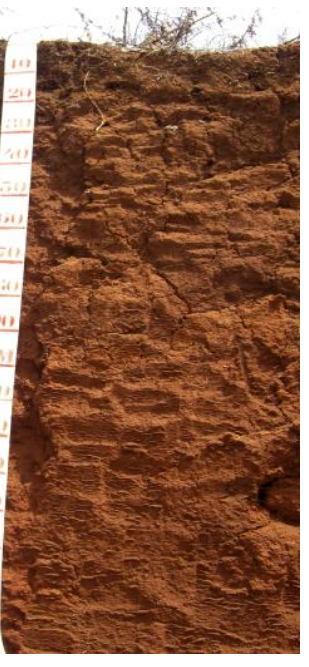

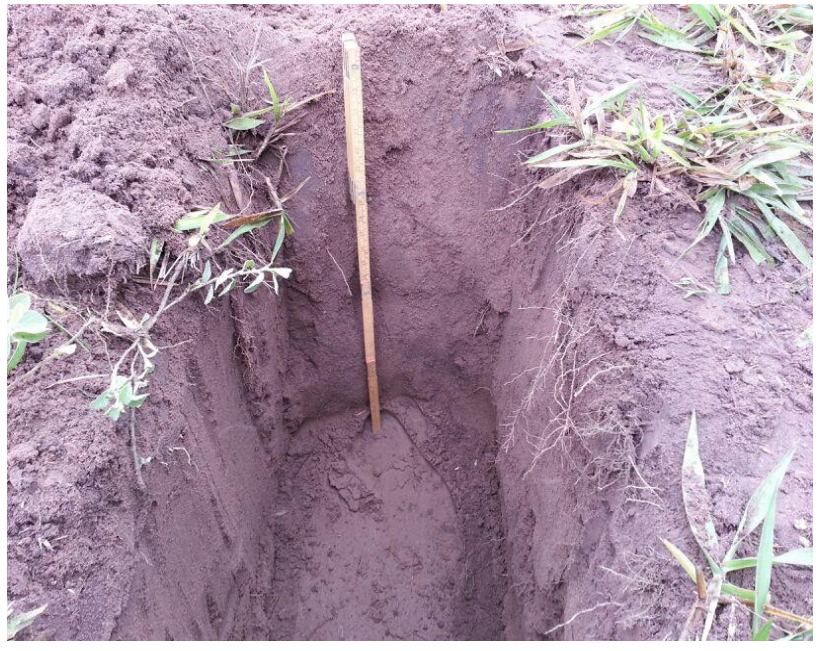

Photo: G. Torres

Supplement Figure S7 (a) Similar soil profile to the Ferralsols to the one found in the cropland catchment and (b) profile of the Arenosols in the pasture catchment, also found in the cerrado catchment.

EMBRAPA, http://www.agencia.cnptia.embrapa.br/Agencia16/AG01/arvore/AG01_96_10112005101956.html, last access: 10 May 2015. 